\title{
Work motivation and temporary organizing - an overview of the state and perspectives of reward practices in project-based organizations
}

\author{
Maja Klindžić, PhD \\ Organization and Management \\ Faculty of Economics and Business \\ University of Zagreb \\ Zagreb, Croatia \\ $\underline{\text { mklindzic@efzg.hr }}$
}

\author{
Rebeka D. Vlahov, PhD \\ Organization and Management \\ Faculty of Economics and Business Zagreb \\ University of Zagreb \\ Zagreb, Croatia \\ rvlahov@efzg.hr
}

\begin{abstract}
Projects, project-oriented or project-driven companies have emerged as the most popular forms of temporary organizing in the last couple of decades. While marginalized in the past, people factor has appeared as one of the most important factors of project success, and human resource management issues are consequently generating more knowledge on principles and practices of motivating and rewarding individuals and team members in project-based organizations. In this review paper, a desk-research was undertaken in order to analyse available studies on motivating and rewarding project teams, and several research questions that can potentially fill in the gaps present in the literature were revealed. More precisely, conclusions and research gaps were divided into five broad areas: (1) cross-sectional nature of data gathered by available studies, (2) separation of available motivation and reward practices examined in research so far, (3) generic application of reward practices and conclusions without taking into account independent characteristics of individuals, organizations and industries, (4) potential application of new reward management concepts to project teams, and (5) reward management problems related to various roles and responsibilities of project management stakeholders.
\end{abstract}

Keywords - temporary organizing, project-based organizations, work motivation, reward management, human resource management

\section{INTRODUCTION}

The development of temporary and democratic work forms has been an important characteristic of work for some time now [1], and projects, projectoriented or project-driven companies have emerged as the most popular forms of temporary organizing. Previously, many studies were focused on project success factors [2,3] while projects were treated as technical and not behavioural systems [4]. Today, there is no doubt that human resource (HR) factor is determining the project success in a large part [5] and there are at least four challenges that are important in development of Human Resource Management (HRM) to meet the requirements of project operations, as identified in the seminal study [6]: "the competence issue, the trust issue, the change issue, and the people issue".

People or personnel factor has meanwhile evolved from being marginal [4] to being extensively studied and acknowledged. In recent years, a lot has been done in relation to project management qualification and certification programs [7] or, alternatively, in identifying key project management skills and competencies [8, 9]. However, a more systematic approach is needed in order to effectively manage people issues during project phases. Generally speaking, HRM has neglected many HR functions such as retention, as well as career possibilities and design for project managers [10]. In fact, the HR perspective on project management in general [11, 12] was considered very rudimental [4] up until recently.

While many functions of HRM have been insufficiently researched in the context of project management, the one that deals with motivating project managers and project management teams has generated the least theoretical and practical insights. This comes as a surprise since it has been previously established that motivation should be perceived as the key factor in successful project management due to the fact the absence of motivation is the most frequent cause of the failure in this field [10, 13]. Despite the lack of attention to motivation management, one of the most difficult challenges HR professionals are facing nowadays involves finding the right models of compensation for teams and team members which, on the one hand, will be fair and efficient, while, on the other hand, provide incentives for enhancing productivity and performance [14]. In fact, the need for increasing project managers' motivation becomes the main concern for organizations [15, 13], since many project managers do not consider to be adequately respected and compensated for the work they are performing [10]. According to Peterson, project manager also needs to understand the reason for demotivation in order to be able to create and maintain a motivating environment for all project team members and achieve project success [16]. 
Based on the importance that is placed on motivation management, reward structures and their relationship to productivity and project success, we build on the available knowledge on HRM in general, as well as on work motivation and reward management in project management structures, in order to analyse the state and perspectives for future research in motivation of project managers and team members. The rest of the paper is organized as follows - we give a brief overview of key aspects of temporary organizing, project-based structures and project management specificities; next, we draw on previous research to describe the main problems related to HRM in project-based structures; finally, in the fourth part of the paper, we give an overview of work motivation and reward management concepts in general, followed by an analysis of available research that investigates work motivation in project teams. In that part, we also reflect on the insights generated by the analysis and propose recommendations to fill in the gaps present in the area of project and HR management.

\section{TEMPORARY ORGANIZING, PROJECT- BASED ORGANIZATION AND PROJECT MANAGEMENT SPECIFICITIES}

Temporary organizations represent a common and important part of economic and social life today [17]. In fact, an increasing number of organizations, in growing and mature industries alike, is creating dynamic work environments which involve frequent adaptations to opportunities and changes from the market with the use of temporary work forms like projects and programs [6, 18, 10, 19]. Additionally, previous research has also documented a significant rise of temporary organizing principles in and across firms which can include managing short-term projects and forming dedicated temporary organizations, navigating project networks, hiring temporary contract workers and orchestrating field-configuring events such as conferences, or maintaining temporary clusters like trade fairs [19]. Since these types of structures include creating unique products or services within performance constraints and environmental uncertainties, cross-functional skills are needed for them to operate successfully [20].

Temporary organizations regardless the type are designed by and around people [17] and are dependent on the will, commitment and ability of individuals for their creation, development and termination $[17,18]$. As projects are the most popular form of temporary organizing [18], a wide variety of objectives, with numerous internal and external actors from different sectors have to be taken into consideration [4]. As stated by Gareis and Huemann, in project-based organizations, projects are not only tools for performing complex processes, but also a strategical option for the organizations dealing with an increasingly complex business environment [21]. In that sense, temporary organizations like projects or programs could differentiate the organization and decentralize the management responsibility, flatten the organization, assure quality using project teamwork and integrate different types of knowledge and skills [22], be goal-oriented and develop personnel, as well as learn by projects at the organizational level $[23,6]$.

Project-oriented companies are social constructs with specific organizational strategy, structures and culture based on management concepts like Lean Management, Total Quality Management, Learning Organization and Business Process Re-Engineering, and focused on managing a project portfolio comprised of different internal and external projects [24]. They represent fast and flexible way of temporarily organizing the resources, needed for overcoming traditional barriers to organizational change $[25,26]$ and usually with established professional project management certification systems, clearly defined project management career paths [27] and sometimes even project management office engaged in monitoring project quality and improvement [12]. By continuously developing the project operations, this kind of organizations are able to achieve and sustain competitive advantage in the market $[25,28,6]$.

Project work is of importance in the public and private sector for growing and mature industries alike, with the emphasis on the industries that seem to be especially project-intensive: advertising, automotive, consulting, IT, entertainment, media and pharmaceutical [29, 6, 30]. The work is performed by cross-functional project teams comprised of people with the specific competencies [6], usually coordinated by the project manager responsible not only for the proper functioning of the team, but also for the successful delivery of project deliverables [31, $32,4]$. However, if the project manager and project team members are only considered within a project as a temporary organizational form which will be resolved at the end, they face continuous uncertainty regarding their future role in the organization [10]. Therefore, to properly manage and complete a project, project team has to overcome many documented challenges related to: "individual differences, role definitions, clarity of project objectives, dynamic project environments, credibility of the project leader, commitment, communication and senior leadership support" [4]. Previous research in the field shows that the motivational environment in which teams operate is of critical importance in determining employee behaviour, while the effective collaboration among project team members is of the utmost importance for the project success [4, 33, 34]. This is especially important since team members can have multiple roles, work in different projects at the same time, and with multiple project managers, teams, clients and line managers $[11,35]$.

\section{HRM IN PROJECT-BASED ORGANIZATIONS}

Managing people in organizations has significantly changed in the western world from the 1980s onwards, i.e. from personnel to HR management [36]. While clearly defined and 
structured in large and stabile organizations, it is still a challenge to define how HRM should be used in temporary organizations based on projects $[6,11,12]$. The move towards project-based structures has implications both for employees and HRM [37], however, only a few examples exist where the unique requirements and challenges are documented [10].

As the importance of the temporary project-based work settings increases, existing HR practices have to be adapted, with a special focus put on team aspects $[6,11]$. Specific features of the project-oriented organizations such as their strategy, temporary nature of projects, multirole demands, dynamics and allocation of the resources [32, 38, 24] produce special requirements, therefore putting pressure to change the HR configuration every time when a new project or program starts [11]. Projects represent everyday working environment in which individuals build their careers and competencies, develop their reputation and gain critical experience for future project assignments [37].

Among challenges associated with HRM in project management, several areas stand out. For example, in order to build long-term competitiveness, it is crucial to attract core talents and integrate their efforts with the firm's strategic processes and projects [6]. Also, working in multi-project environments seems to increase the risk of excessive workload which may results in less time that can be spent on reflection and learning, as well as recuperation between the projects, which may also interfere with the competence development [39]. In addition, project-based organizations do not provide much time for formal training and staff development [37]. Finally, previous research show that people coming from organizations that are considered to be nonprojectized who are working on projects show less mental health than those people who are coming from projectized organizations [40].

Apart from the fact that several HRM functions are neglected or under-utilized in the project-oriented organizations, another particular problem, especially pronounced in a matrix environment, arises from the division of roles between line and project managers. HRM in the project-oriented company is considered to be more decentralized, requiring HRM tasks to be carried out by the HR department, line and project managers $[6,26]$. In order to transform a stable organization into a project-oriented one, major changes in HRM services, processes and roles also have to be done. More specifically, Huemann et al. explain how project-oriented organizations need to adapted line and project HRM processes [11]. Therefore, the role of the line manager includes competence management focused on the HR issues like employing people on the project, developing their competencies and managing their careers [37]. When it comes to one of the crucial work aspects motivation and reward management - taking into account that employees are part of project teams for a limited period of time, their long-term performance, reward and career management should also be in the scope of the line organization [41, 12]. The project manager, on the other hand, doesn't only have the obligation to give the direct feedback to employees, but also helps the line managers with the evaluation and review processes [37]. HRM in such a context should be a matter of supporting and counselling to help employees in finding balance between high- and low-intensity periods of work [6]

Building on the previously mentioned facts, all HRM tasks should be carried out as a joint work of the HRM department, line and project managers [6, 26, 12]. However, cooperation between them to support the project-oriented companies is often not at a satisfactory level [42] and companies struggle with aligning HRM with their needs [12]. Even though it is expected that individual project workers have increased responsibility for a variety of HRM processes and activities [43, 44, 37], when it comes to what is often cited as primary concern in project management and project-oriented organizations, i.e. motivation and reward management practices $[14,15$, 13], cooperation between all three parties might be crucial in delivering results.

\section{WORK MOTIVATION AND REWARD MANAGEMENT PRACTICES IN PROJECT- BASED ORGANIZATIONS}

\section{A. Work motivation, reward management and team structures in contemporary business}

Work motivation refers to a mixture of external and internal forces [45] that trigger work-related behaviour and determine its form, intensity, direction and duration [46]. Work motivation is more likely to affect essence of organizations that are labourintensive as well as in companies where employees have greater control over both the means and level of production [45], such as project-oriented companies. In business organizations, rewards or incentives are applied in order to affect motivation [47], i.e. to guide employee behaviour [48]. In fact, one of the most important activities for HR professionals is to construct a reward strategy that would motivate employees and secure high organizational performance. Compensation is a crucial factor of organizational strategy since it affects firm performance by attracting and retaining high ability employees and by motivating employee effort $[49,50$, 51].

Compensation is usually thought of as a sum of base pay, pay-for-performance incentives and benefits, i.e. all financial rewards that an employee can obtain for work performed [50]. While direct monetary compensation in the form of base pay is a steady source of income providing security for employees [52], indirect compensation or benefits are more likely to influence a sense of belongingness to the company [51]. The third element, variable individual or team pay is often cited as a primary tool in eliciting economic behaviour [53] that results in better business performance [51]. Nowadays, however, direct and indirect financial rewards are 
perceived mostly as extrinsic motivators, i.e. those that come from external factors or environment. Intrinsic motivation, on the other hand, comes from within, and in that case, employees are motivated because of internal satisfaction of pride in expertise and responsibility [54]. According to Herzberg and associates, the advancement, achievement and recognition were labelled as intrinsic rewards that motivate the employees more than the extrinsic rewards, i.e., salary or working environment $[51,55]$. Though many employers place emphasis on extrinsic rewards, the 'crowding out' effect on intrinsic motivation has emerged as a major criticism of the use of financial remuneration and incentives to promote motivation. More precisely, because monetary rewards decrease task-specific intrinsic motivation, intrinsic effort in general is lower [see 56]. Therefore, it is important to combine both extrinsic and intrinsic motivators in attempt to generate favourable individual performance and, consequently, team, group and organizational performance as well.

Against the backdrop of increasingly adopting teams and teamwork as dominant work units, teambased compensation clearly needs to complement performance measurement [57]. The intention behind this idea is, among other things, to foster cooperation among team members, promote team productivity, and overcome limitations of larger team-based plans by focusing on rewards in which a portion of individual pay is dependent on measurable group performance and achievement of team goals [57, 8]. Team-based settings, such as project teams, however, present special problems for reward systems [14].

Because team members often have diverse or even conflicting goals as well as different levels of commitment to the team and the shared task, motivating teams adds a lot of convolution to the choice of managerial interventions [58]. Additionally, as team motivation consists of both the collective orientation toward helping the team to succeed and individual effort toward the attainment of individual tasks [59], organizations generally rely either on shared or individual rewards to motivate workers to reach team goals [57]. According to De Dreu et al., although team-based rewards encourage motivation by focusing on attention and effort towards interaction between team members, they at the same time reduce member accountability and effort [60]. On the other hand, individual rewards result in higher member satisfaction and a stronger connection between behaviour and outcomes but can fail to encourage members to focus attention towards team cooperation and helping behaviour [60]. The choice between would be contingent primarily on the level of team task interdependence, i.e. the degree to which the team's task performance depends on the organized work and skills of all team members [61].

\section{B. Factors of motivation in project-based organizations}

Team motivation without a doubt plays a key role in project. Therefore, project manager's knowledge of what motivates team members and of techniques to influence the team to keep the project on a successful path [15] is one of the essential skills team leaders should possess. However, while a lot has been written on the motivational techniques of top, middle and low-level managers, quite less is known about the unique motivational structure of project managers [10]. It is often postulated that, in order to have high performing teams, project managers have to be both self-motivated and be able to motivate their team members [16, 13]. On the other hand, Seiler et al. criticize the notion of ,a self-motivated project manager" and argue that, instead of focusing on what motivates project managers, focus should be on how project managers can motivate their team members [13]. Because the bottom line of motivation is inspiration, courage, and stimulation to achieve common goals through teamwork, Peterson argues that project manager's first and the foremost interest should be to drive towards project success the creation and maintenance of a stimulating motivating environment for all members of the project team [16]. In order to motivate a team member for high performance, Peterson further explains that a project manager is required to possess many different interpersonal skills [16]

Based on the tasks and challenges associated with working in projects, Gällstedt assumes a strong intrinsic motivation [1]. This hypothesis has been studied in several contexts. The earliest studies indeed cited mostly intrinsic factors such as recognition for personal achievement, a sense of belonging and making a contribution, receiving positive feedback, creative autonomy, believing in what one does etc. as motives and drivers for project managers and project teams $[62,63,64]$, even though extrinsic motivators such as a reward system and work conditions were acknowledged as well [63]. Subsequent empirical studies have shown different results, with some of them being described in the following part of the paper.

The study of Ghoddousi et al. was based on data from 194 site-based construction workers in Iran to test the proposed model of motivation [65]. The study revealed that the proposed model of expectancy theory incorporating five different indicators can be applied to map the process of motivating construction workers. More specifically, their findings posit that intrinsic indicators could be more effective than extrinsic ones. In the study of Mahaney and Lederer, different types of rewards were associated with various project outcomes [66]. A couple of hundred members of the Project Management Institute completed the survey which revealed that the client satisfaction and perceived quality (but not implementations success in regard with time and budget) could be predicted by the use of intrinsic rewards, while the use of extrinsic rewards predicted 
implementation success (but not satisfaction or quality) [66].

The study conducted by Grille et al. investigated the influence of intrinsic and extrinsic facilitators and vertical leadership [67]. Data from 328 team members nested in 67 work teams and their respective team leaders were analysed, and the results showed that perception of psychological empowerment as an intrinsic factor, and perception of being fairly rewarded as an extrinsic factor, were associated with shared leadership. Also, appreciation from the leader and colleagues appears to be an important extrinsic motivator, together with financial rewards (salary increase, bonuses and career options). Grille et al. concluded that financial reward and appreciation are positively related to teamwork outcome when they are considered fair in terms of personal investment in relation to rewarding outcome, they [67].

Managers and executives from 257 organizations completed online surveys conducted by Howard et al. who analysed relations among task interdependence, reward strategies, team performance, and firm productivity [14]. Results revealed higher levels of productivity for companies that based employee rewards on either personal or collective output [14]. At the same time, no direct relationships with team performance was found for output-based reward strategies [14]. Interestingly, Sarin and Mahajan found a nonlinear and monotonically decreasing relationship between outcome-based rewards and product quality for risky projects and highly competitive or relatively stable industries [68].

In the study of Schmid and Adams, was used to discover perceptions regarding team motivation by project management professionals in PMI online research network [15]. The results of this study identified factors that most commonly provoke a decrease in team motivation such as personal conflicts between team members, the lack of top management support, and an increase in project scope. Additionally, intrinsic motivation seems to be a crucial factor in delivering projects, according to the same research. In order to develop a sense of belonging and owning, team members must be involved in the project from the early kick-off stage to [15]. In fact, the vast majority of the project manager respondents $(90 \%)$ stated that the essential step to maintain team motivation was having team members participate in the creation of the work breakdown structure.

Seiler et al. developed and evaluated an integrated model of factors influencing project managers' motivation - "Motivational Factor Inventory" (MFI) [13]. Study results showed that the MFI was a valid instrument and that all identified items were relevant for the motivation of the project manager. More precisely, the most important motivators for project managers working in Switzerland were: a clearly defined, interesting task, working with a supportive and goal-oriented team, getting the necessary information and financial and personnel resources, as well as having the possibility to influence important decisions [13]. Interestingly enough, factors related to compensation i.e. reward management were the least important motivators [13]. Additionally, age has been confirmed as a significant moderator, where both learning opportunities and support for the right balance between workload and private life were more meaningful to younger than to older project managers [13].

The research conducted by Stare on a sample of Slovenian companies showed that only one-third of examined enterprises had implemented reward systems [69]. At the same time, project organizational culture along with rewards was found to increase the motivation of team members and consequently reduces project delays and cost overruns [69]. Additionally, rewards in general were moderately correlated with team motivation; however, the correlation analysis showed that monetary rewards were not directly correlated with efficient project execution [69]. The correlation analysis also revealed a relationship among top and line management attitude (as particular project culture factors) and the implemented rewards - it seems that rewards are mainly implemented in enterprises with a high level of project culture [69].

Finally, Zhu et al. collected data from R\&D engineers and their managers in a large high-tech company headquartered in Taiwan [70]. Results indicate that a collaborative team climate has a direct positive relationship with creativity, but also indirect effects through individual motivation [70]. A competitive team climate was positively related to extrinsic motivation; however, extrinsic motivation did not show a direct relationship with creativity [70]. Also, extrinsic motivation did have strong relationships with creativity when intrinsic motivation was low, therefore, results suggest that different types of motivation could be related to different types of creativity [70].

\section{Research gaps and recommendations for future research}

Research on work motivation factors and reward management practices in project-based organizations has not received considerable attention as one would expect. Out of a dozen analysed studies that dealt with certain aspects of work motivation, several conclusions were drawn, and a couple of research gaps identified. More precisely, we divided those conclusions and research gaps into five broad areas: (1) the cross-sectional nature of data gathered by available studies, (2) generic application of reward practices and conclusions without taking into account independent characteristics of individuals, organizations and industries, (3) the nature and separation of available motivation and reward practices in research so far, (4) potential application of new reward management concepts to project teams, and (5) reward management problems related to various roles and responsibilities of project management stakeholders. 
First of all, studies are almost exclusively crosssectional in nature and have captured perceptions and attitudes that could have been held true at the time of the data gathering. Work motivation also changes over time as a function of the external forces which create the world of an individual [45] and these changes should be captured by longitudinal research as well. Moreover, projects, as temporary structures, consist of several phases, with each phase carrying its unique characteristics, roles, responsibilities, skills, knowledge and risks [32], so future research could try to investigate factors of motivation in each of these project phases. A contribution was made by Schmid who found that the project manager's attention to motivation system and techniques appears to be crucial at the beginning of a project [15]; however, more insights into factors of motivation that drive team members to be actively engaged in each project phase are needed. More precisely, it is often cited that even though project participants are motivated by the challenge of reaching project goals, tight completion dates often put pressure and stress on them [1]. In fact, most project managers will state that they work overtime which causes a lot of stress and exhaustion [40]. Project managers, in that case, should strive to find ways to keep themselves and team members motivated, involved and engaged while at the same time they should be able to answer stress-related problems and pressures ${ }^{1}$ that are inevitable in projects.

Second, most studies generate somewhat generic conclusions about what motivates project team members and project managers without taking into account the independent characteristics of individuals, organizations and cultures, to name a few. For example, we suggest taking into consideration individual characteristics, i.e. the differences in motivation factors with regard to (a) gender research so far has neglected the unique characteristics of both men and women, and their motivation needs even though these differences have been acknowledged in many other management areas [see 71]; (b) age - different needs, expectations and attitudes are nowadays well established in the management literature from the perspective of either "younger versus older employees" [see 13] or between "different generational cohorts" of employees, i.e. Baby Boomers, X, Y and Z; (c) education - mostly in terms of obtained university degrees, research could take into account potential differences between, e.g. economists and engineers. Additionally, higher-level independent differences could be included, such as (d) industry - project teams in construction are potentially very different

\footnotetext{
${ }^{1}$ Interestingly, a piece of research finds that this negative effect on individuals' health only occurs if pressure is not experienced as a challenge [1]. On the other hand, negative relationship was found between project involvement levels of psychological distress [39]. This is explained by the fact that, despite its challenges, project work is perceived as more challenging and rewarding than routinized work [39].
}

from IT or public sector teams; and (e) culture - many studies analysed in the previous section come from cultures that differ significantly from cultural dimensions' point of view (e.g. Iran, Switzerland, Taiwan, Slovenia, USA). Future research should attempt to capture both the influence of the unique characteristics of particular countries, as well as the same differences in culturally diverse teams that might operate in a single country.

Thirdly, even though several studies have explored both extrinsic and intrinsic factors of motivation among project team managers and members, we found almost no study other than the one conducted by Pearsall et al. who investigated the joint effect of various motivation factors and reward types on project outcomes [58]. More precisely, they found the highest levels of team performance for highly interdependent teams that were compensated by hybrid reward structures (i.e., structures that reward individual and team effort and accomplishment simultaneously) [58]. Therefore, the combination or a mix of individual and group, as well as extrinsic and intrinsic motivators, should be taken into account when designing high-performance project teams. As a matter of fact, the proposition to investigate a set, combination or a mixture of different reward practices is backed up by MacDuffie, according to whom "the appropriate unit of analysis for studying the link between different HR practices and competitiveness is an interrelated and internally consistent 'bundle' of practices, rather than individual practices" [72]. Such 'bundles' create a large number of supporting conditions that, according to Perry-Smith and Blum, are consistent with strategic HRM idea of increasing company economic performance, with human resources as a primary source of sustainable competitive advantage [73].

Fourth, and building on the previous insight, a more integrated approach to motivation and reward management is needed in project-based organizations. It is often postulated that, in order to keep and motivate project managers and project team members, as well as to prevent the loss of valuable project management know-how and expertise, the organization needs to develop a holistic yet integrated incentive system [10]. In fact, a holistic approach to reward strategy can have a significant impact on HR decisions and, consequently, on business results as well. However, even organizations that appreciate the value of an effective reward strategy struggle with the actual task of creating and implementing one [74]. In an attempt to do so, researchers and practitioners have developed a framework called "The Total Reward Model" that integrates both types of rewards, i.e. material and non-material ${ }^{2}$ with neither being perceived as more important than the other [see 75, $54,55]$. It would be interesting to examine how the integration between various model elements such as direct compensation, benefits, learning and

\footnotetext{
2 In "Total Reward Model" these are usually referred to as „transactional“" and ,relational“ rewards.
} 
development, and work environment influences project teams' effectiveness and efficiency.

Finally, little has been written about reward management roles and responsibilities of different members in the project-oriented organization, namely - the line manager and the project manager. In practice, project members can often find themselves caught between the command and control structures i.e. project and at-line/functional level [26]. In project-intensive firms, line managers often have problems understanding the work and emotional situation of the individual project worker [37]. A piece of research conducted by Dunn on 18 matrixtype organizations on influence or control for factors that result in job satisfaction or dissatisfaction indicates that project managers have significant responsibility for the well-being of project team members [31]. According to the same research, functional managers have control or influence factors that do not lead to higher motivation or job satisfaction, while project managers have significant control or influence for the motivating factors [31]. While everyday work is supervised by project managers, longer-term performance, reward and career management often take place within the line organization [11, 26]. Project managers play a key role in evaluating the performance of project personnel, but tensions may emerge if line managers do not recognize the achievements of the project participant sufficiently during performance appraisals, and do not always actively involve project managers in the process [26]. More research is needed in order to design motivation and reward systems in a way that would minimize conflicts between project and line managers.

\section{CONCLUSION}

In this paper, we presented a review of relevant work on temporary organizations, specifically projectoriented ones. Based on the importance that is placed on motivation management, reward structures and their relationship to productivity and project success, we build on the available knowledge on HRM in general, as well as on work motivation and reward management in project management structures specifically. Out of a dozen analysed studies that dealt with certain aspects of work motivation, we have drawn the conclusions and identified several research gaps which offer enormous opportunities for empirical examination with an aim to make important contributions to the field of managing people in project-based organizations.

\section{REFERENCES}

[1] M. Gällstedt, "Working conditions in projects: perceptions of stress and motivation among project team members and project managers, "International Journal of Project Management, vol. 21, pp. 449-455, 2003.

[2] V. S. Anantatmula, and P. F. Rad, "Role of Organizational Project Management Maturity Factors on Project
Success," Engineering Management Journal, vol. 30, pp. 165178, 2018.

[3] T. Cooke-Davis, "The "real" success factors on projects," International Journal of Project Management, vol. 20, pp. 185-190, 2003

[4] A. Belout, and C. Gauvreau, "Factors influencing project success: the impact of human resource management," International Journal of Project Management, vol. 22, pp. 1$11,2004$.

[5] Z. Wong, Human Factors in Project Management: Concepts, Tools, and Techniques for Inspiring Teamwork and Motivation, San Francisco: Jossey-Bass, 2007

[6] J. Söderlund, and K. Bredin, "HRM in project-intensive firms, changes and challenges, "Human Resource Management, vol. 45 , pp. $249-265,2006$

[7] IPMA, Individual Competence Baseline for Project, Programme \& Portfolio Management $-4^{\text {th }}$ Version, Nijkerk: International Project Management Association, 2015.

[8] F. Aime, C. J. Meyer, and S. E. Humphrey, "Legitimacy of team rewards: Analyzing legitimacy as a condition for the effectiveness of team incentive designs, " Journal of Business Research, vol. 63, pp. 60-66, 2010.

[9] C. C. Silva de Araújo, and C. Drebes Pedron, "IT project manager competencies and IT project success: a qualitative study,“ Organisational Project Management, vol. 2, pp. 53-75, 2015 .

[10] K. Hölzle, "Designing and implementing a career path for project managers," International Journal of Project Management, vol. 28, pp. 779-786, 2010.

[11] M. Huemann, A. Keegan, and J. R. Turner, "Human resource management in the project-oriented company: A review," International Journal of Project Management, vol. 25, pp. 317-323, 2007.

[12] M. Huemann, "Considering Human Resource Management when developing a project-oriented company: Case study of a telecommunication company, “ International Journal of Project Management, vol. 28, pp. 361-369, 2010.

[13] S. Seiler, B. Lent, M. Pinkowska, and M. Pinazza, "An integrated model of factors influencing project managers' motivation - Findings from a Swiss Survey," International Journal of Project Management, vol. 30, pp. 60-72, 2012.

[14] L. W. Howard, D. B. Turban, and S. K. Hurley, "Cooperating Teams and Competing Reward Strategies: Incentives for Team Performance and Firm Productivity," Journal of Behavioral and Applied Management, vol. 3, pp. 249-267, 2002.

[15] B. Schmid, and J. Adams, "Motivation in Project Management: The Project Manager's Perspective," Project Management Journal, vol 39, pp. 60-71, 2008.

[16] T. M. Peterson, "Motivation: How to increase project team performance," Project management journal, vol. 38, pp. 6069, 2007.

[17] R. A. Lundin, and A. Söderholm, "A theory of the temporary organization," Scandinavian Journal of Management, vol. 11, pp. 437-455, 1995.

[18] R. M. Bakker, R. DeFillippi, A. Schwab, and J. Sydow, "Temporary organizing: Promises, processes, problems.“ Organization Studies, vol. 37, pp. 1703-1719, 2016.

[19] R. Sydow, "Temporary Organizing - The End of Organizations as We Know Them?," Rutgers Business Review, vol. 2, pp. 199-205, 2017.

[20] C. N. Bredillet, and R. Dwivedula, "Profiling work motivation of project workers," International Journal of Project Management, vol. 28, pp. 158-165, 2010. 
[21] R. Gareis, M. and Huemann, "Project Management Competencies in the Project-oriented Organisation" in The Gower Handbook of Project Management, J. R. Turner and S. J. Simister, Eds., New York: Routledge, 2000, pp. 709-721.

[22] M. Hobday, "The project-based organisation: an ideal form for managing complex products and systems?," Research Policy, vol. 29, pp. 871-893, 2000.

[23] P. W. G. Morris, The management of projects, London: Thomas Telford, 1994.

[24] R. Gareis, Happy Projects!, Vienna: Manz, 2005.

[25] T. Brady, and A. Davies, "Building project capabilities: from exploratory to exploitative learning," Organization Studies, vol. 25 , pp. 1601-1619, 2004

[26] A. Keegan, M. Huemann, and J. R. Turner, "Beyond the line: exploring the HRM responsibilities of the line managers, project managers and the HRM department in four projectoriented companies in the Netherlands, Austria, the UK and the USA," The International Journal of Human Resource Management, vol. 23, pp. 3085-3104, 2012.

[27] E. Borg, and J. Söderlund, ”Moving in, moving on: liminality practices in project-based work," Employee Relations, vol. 36, pp. 182-197, 2013.

[28] J. Söderlund, "What project management really is about: alternative perspectives on the role and practice of project management," International Journal of Technology Management, vol. 32, pp. 371-387, 2005.

[29] S. Godenhjelm, R. A. Lundin, and S. Sjöblom, "Projectification in the public sector-the case of the European Union," International Journal of Managing Projects in Business, vol. 8, pp. 324-348, 2015.

[30] Y. G. Schoper, A. Wald, H. T. Ingason, and T. V. Fridgeirsson, "Projectification in Western economies: A comparative study of Germany, Norway and Iceland" International Journal of Project Management, vol. 36, pp. 7182., 2018.

[31] S. C. Dunn, "Motivation by Project and Functional Manager sin Matrix Organizations, “ Engineering Management Journal, vol 13., pp. 3-9, 2001

[32] J. R. Turner, and R. Müller, "On the nature of the project as a temporary organization" International Journal of Project management, vol. 21, pp 1-8., 2003.

[33] D. D. Gransberg, H. L. Reynolds, and J. Boyd, "Measuring partnered project performance," Cost Engineering, vol. 41, pp. 39-44, 1999.

[34] M. C. Caniëls, F. Chiocchio, and N. P. van Loon, "Collaboration in project teams: The role of mastery and performance climates," International Journal of Project Management, vol. 37, pp. 1-13, 2019.

[35] A. Keegan, and D. D. Hartog, "Doing it for themselves? Performance appraisal in project-based organisations, the role of employees, and challenges to theory, " Human Resource Management Journal, pp. 1- 21, 2018.

[36] N. Pološki Vokić, M. Klindžić, and T. Hernaus, "Changing HRM practices in Croatia: Demystifying the impact of the HRM philosophy, the global financial crisis and the EU membership,"Journal for East European Management Studies, vol. 23, pp. 322-343, 2018.

[37] K. Bredin, and J. Söderlund, Human resource management in project-based organizations: The HR quadriad framework, London: PALGRAVE MACMILLAN, 2011.

[38] J. Sydow, L. Lindkvist, and R. DeFilippi, "Project-Based Organizations, Embeddedness and Repositories of Knowledge: Editorial," Organization Studies, vol. 25, pp. 1475-1489, 2004
[39] A. Zika-Viktorsson, P. Sundström, and M. Engwall, "Project overload: An exploratory study of work and management in multi-project setting," International Journal of Project Management, vol. 24, pp. 385-394, 2006.

[40] F. Chiocchio, G. Beaulieu, J. S. Boudrias, V. Rousseau, C. Aubé, and E. M. Morin, "The Project Involvement Index, psychological distress, and psychological well-being: Comparing workers from projectized and non-projectized organizations," International Journal of Project Management, vol. 28, pp. 201-211, 2010.

[41] K. B. Clark, and S. C. Wheelwright, "Organizing and leading "heavyweight" development teams," California management review, vol. 34, pp. 9-28, 1992.

[42] J. R. Turner, M. Huemann, A. E. Keegan, Human Resource Management in the Project-oriented Organization: the roles of project managers, line managers, and HRM managers, Newtown Square: Project Management Institute, 2008.

[43] M. B. Arthur, R. J. DeFillippi, C. and Jones, "Project-Based Learning as the Interplay of Career and Company NonFinancial Capital,“ Management Learning, vol. 32, pp. 99117,2001

[44] J. Garrick, and S. Clegg, "Stressed-Out Knowledge Workers in Performative Times: A Postmodern Take on Project-Based Learning," Management Learning, vol. 32, pp. 119-134, 2001

[45] R. Kanfer, G. Chen, and R. D. Pritchard, "The Three C's of Work Motivation: Content, Context, and Change," in Work Motivation: Past, Present, and Future, R. Kanfer, G. Chen, and R. D. Pritchard, Eds. New York: Routledge - Taylor \& Francis Group, pp 1-16, 2008.

[46] C. Pinder, Work Motivation in Organizational Behavior, New York: Psychology Press, 2014.

[47] M. Van Herpen, M. Van Praag, and K. Cools, "The effects of performance measurement and compensation on motivation: An empirical study," De Economist, vol. 153, pp. 303-329, 2005 .

[48] L. Gomez-Mejia, and D. Balkin, "Effectiveness of Individual and Aggregate Compensation Strategies," Industrial Relations, vol. 28, pp. 431-445, 1989.

[49] I. Larkin, L. Pierce, and F. Gino, "The Psychological Costs of Pay-For-Performance: Implications for The Strategic Compensation of Employees," Strategic Management Journal, vol. 33, pp. 1194-1214, 2012.

[50] J. M. Newman, B. Gerhart, and G. T. Milkovich, Compensation, New York: McGraw-Hill Higher Education, 2016.

[51] S. Perkins, G. White, and S. Jones, Reward Management: Alternatives, Consequences and Contexts. London: CIPD, 2016.

[52] L. Galetić, Kompenzacijski menadžment (Compensation Management), Zagreb: Sinergija, 2015.

[53] M. Trisolini, "Theoretical Perspectives on Pay for Performance," in Pay for Performance in Health Care: Methods and Approaches, J.Cromwell, M. G. Trisolini, G. C: Pope, J. B. Mitchell, and L. M. Greenwald, Eds. New York: RTI Press publication, pp. 77-98, 2011.

[54] B. Mujtaba, and S. Shuaib, "An Equitable Total Rewards Approach to Pay for Performance Management," Journal of Management Policy and Practice, vol. 11,pp. 111-123, 2010.

[55] T. Nazir, S. Shah, and K. Zaman, "Literature review on total rewards: An international perspective," African Journal of Business Management, vol. 6, pp. 3046-3058, 2012.

[56] T. Rose, and K. Manley, "Client recommendations for financial incentives on construction projects," Engineering, Construction and Architectural Management, vol. 17, pp. 252267, 2010. 
[57] J. S. DeMatteo, L. T. Eby, and E. Sundstrom, "Team-based rewards: Current empirical evidence," Research in organizational behaviour, vol. 20, pp. 141-183, 2008.

[58] M. J. Pearsall, M. S. Christian, and A. P. Ellis, "Motivating interdependent teams: Individual rewards, shared rewards, or something in between?" Journal of Applied Psychology, vol. 95, pp. 183-191, 2010.

[59] R. P. DeShon, S. W. K. Kozlowski, A. M. Schmidt, K. R. Milner, and D. Weichmann, "A multiple goal, multilevel model of feedback effects on the regulation of individual and team performance in training," Journal of Applied Psychology, vol. 89, pp. 1035-1056, 2004.

[60] C. K. W. De Dreu, "Cooperative outcome interdependence, task reflexivity, and team effectiveness: A motivated information processing approach," Journal of Applied Psychology, vol. 92, pp. 628 - 638, 2007.

[61] R. Wageman, and G. Baker, "Incentives and cooperation: The joint effects of task and reward interdependence on group performance“, Journal of Organizational Behavior, vol. 18, pp. 139-158, 1997.

[62] M. Tampoe, L. Thurloway, "Project management: the use and abuse of techniques and teams (reflections from a motivation and environment study)," International Journal of Project Management, vol. 11, pp. 245-250, 1993.

[63] V. K. Verma, Human Resource Skills for the Project Manager: The Human Aspects of Project Management, Upper Darby: Project Management Institute, 1996.

[64] K. R. Linberg, "Software developer perceptions about software project failure: a case study," The Journal of Systems and Software, vol. 49, pp. 177-192, 1999.

[65] P. Ghoddousi, N. Bahrami, N. Chileshe, and M. R. Hosseini, "Mapping site-based construction workers' motivation: Expectancy theory approach," Australasian Journal of Construction Economics and Building, vol. 14, pp. 60-77, 2014.

[66] R. C. Mahaney, and A. L. Lederer, "The effect of intrinsic and extrinsic rewards for developers on information systems project success," Project Management Journal, vol. 37, pp. 42-54, 2006.

[67] A. Grille, E. M. Schulte, and S. Kauffeld, "Promoting shared leadership: A multilevel analysis investigating the role of prototypical team leader behavior, psychological empowerment, and fair rewards," Journal of Leadership \& Organizational Studies, vol. 22, pp. 324-339, 2015.

[68] S. Sarin, and V. Mahajan, "The effect of reward structures on the performance of cross-functional product development teams," Journal of Marketing, vol. 65, pp. 35-53, 2001.

[69] A. Stare, "The impact of a project organisational culture and team rewarding on project performance," JEEMS Journal of East European Management Studies, vol. 17, pp. 40-67, 2012.

[70] Y. Q. Zhu, D. G. Gardner, H. G. and Chen, "Relationships between work team climate, individual motivation, and creativity," Journal of Management, vol. 44, pp. 2094-2115, 2018

[71] N. Pološki Vokić, D. Sinčić Ćorić, and A. Obadić, "To be or not be a woman?," Revija za socijalnu politiku, vol. 24, pp. 253-276, 2017.

[72] J. P. MacDuffie, "Human resource bundles and manufacturing performance: Organizational logic and flexible production systems in the world auto industry," Industrial and Labor Relations Review, vol. 48, pp. 197-222, 1995.

[73] J. E. Perry-Smith, and T. C. Blum, "Work-Family Human Resource Bundles and Perceived Organizational Performance," The Academy of Management Journal, vol. 43, pp. 1107-1117, 2000.

[74] S. E. Gross, and H. M. Friedman, "Creating an effective total reward strategy: Holistic approach better supports business success," Benefits Quarterly, vol. 20, pp. 7-12, 2004.

[75] S. E. Gross, and J. Bundy, "The Ongoing Integration of Total Rewards," Employment Relations Today, vol. 37, pp. 11-17, 2011 